\title{
The future of the regulation of nuclear safety in the EU
}

\section{Miguel Sousa Ferro}

Portuguese Independent Commission for

Radiological Protection and Nuclear Safety

Lisbon University Law School, Portugal

E-mail:miguel@sousaferro.eu

\begin{abstract}
After more than 50 years of a Euratom Community and despite detailed and wide-reaching European rules in neighbouring fields such as radiological protection, the European Union (EU) has so far been unable to adopt rules on the safety of nuclear installations and the management of nuclear waste. After highlighting the limitations of the existing international law in this field, this paper shows that the EU not only has the competency to act, but that such action is highly desirable. It then looks at past and current efforts to produce such EU regulations and analyses their characteristics and the reasons why they are being blocked by a minority of Western member states. A method is proposed to analyse the varying proposals and their inherent usefulness and desirability.
\end{abstract}

Keywords: nuclear safety; management of nuclear waste and spent fuel; Euratom; European regulation.

Reference to this paper should be made as follows: Sousa Ferro, M. (2008) 'The future of the regulation of nuclear safety in the EU', Int. J. Nuclear Law, Vol. 2, No. 2, pp.149-171.

Biographical notes: Miguel Sousa Ferro is a Guest Lecturer at the University of Lisbon Law School and a Researcher at the Portuguese Independent Commission for Radiological Protection and Nuclear Safety, Portugal. He has a Masters in European Studies from the College of Europe and has published papers in the fields of nuclear law, EU law, competition law and constitutional law. He is currently working on a proposal for an overall revision of Portuguese legislation in the nuclear sector.

\section{Introduction}

The rules relating to nuclear safety aim to ensure the functioning of nuclear installations in such a way that it prevents the causing of harm to workers, the public and the environment. While its scope was originally limited to nuclear power plants, the concept has grown to encompass the regulation of other installations within the nuclear fuel cycle, as well as research facilities. For the purposes of this paper, this concept also encompasses radioactive waste management. 
It should be distinguished from the rules on radiological protection, which focus directly on the protection of individuals and cover a much wider range of installations and activities. These two concepts are, however, closely related and it seems to become ever more difficult to establish a clear border between them.

The regulation of both nuclear safety and radiological protection has essentially remained a national prerogative. While states have been willing to cooperate to develop nonbinding standards (and they have done so in many forums), they have been particularly uneager to accept binding rules in this regard.

Indeed, whereas one finds wide-reaching binding international regulations for nonproliferation, nuclear security, transport of nuclear materials, emergency response and third-party liability, there are very few treaties in the areas of nuclear safety and radiological protection. ${ }^{1}$

The International Labour Organisation promoted the first convention in this field at a relatively early stage: the Radiation Protection Convention (C115) of 22 June 1960, currently with 48 contracting parties. ${ }^{2}$ But it was only after Chernobyl that further treaties surfaced through the efforts of the International Atomic Energy Agency (IAEA). Thus, the Convention on Nuclear Safety (hereinafter 'CNS') was adopted on 17 June 1994. Currently with 62 contracting parties, a far cry from the 189 parties to the Non-Proliferation Treaty, it has nonetheless been ratified by every state operating a nuclear power plant. Later came the Joint Convention on the Safety of Spent Fuel Management and on the Safety of Radioactive Waste Management (hereinafter 'Joint Convention') of 29 September 1997. Today, it has 46 contracting parties, including the P5.

All of these treaties are guided primarily by the goal of promoting cooperation, rather than by imposing clear and specified limits on the behaviour of nuclear operators within the contracting parties. The latter two treaties, in particular, were presented as 'incentive instruments' - a polite way of saying that they are binding more in theory than in practice.

Firstly, there is no compulsory mechanism for the resolution of disputes and no sanction whatsoever for a failure to comply with any of the obligations established in these conventions. Even in the case of a dispute between two states that have submitted a declaration recognising the compulsory jurisdiction of the International Court of Justice (under Article 36 of its statute), the end result will most often be the same, not only because of the feature mentioned in the following paragraph, but also because it would be difficult to show compliance with the obligation to seek a friendly settlement with the other party to the dispute.

Secondly, obligations are phrased in such a way as to allow contracting parties as much wiggle room as possible. One example is Article 6 of C115, which obliges states to set radiation exposure limits without any further specification. Another example is Article 7 of the CNS, which obliges states to create a regulatory framework for nuclear safety that includes requirements of licensing and inspection. But with no specification of what should be required in the licensing procedure or of what should be inspected and in which manner, it is all too easy to comply with that provision while remaining far removed from the ultimate objective of ensuring nuclear safety. More often, the use of undetermined concepts such as 'adequate' and 'appropriate' make it impossible to grasp the exact content of the obligation (in the absence of a mandatory jurisdiction which may provide clarifications). 
In short, the CNS and the Joint Convention establish a set of general principles which all states with nuclear power plants can agree on, knowing that they can interpret such principles as they see fit and that they can never be legally charged with infringing the 'obligations' in question.

That is not to say that the principles in themselves are useless. Quite on the contrary, they constitute the fundamental skeleton of any regulatory system in this domain. But too much is riding on how each state chooses to fill the many gaps of the international regime.

\section{The EU's competence to regulate nuclear safety}

As was argued in the previous section, the international law on nuclear safety and radiological protection has an extremely limited reach and depth, which necessarily arise from the inability and/or unwillingness of states to agree on more specific rules of a binding nature.

In the field of radiological protection, the member states of the European Communities have long grown accustomed to Community-wide harmonisation. Based on reputable nonbinding standards such as the recommendations of the International Commission on Radiological Protection, the Radiological Protection Directive (Directive 96/29/Euratom, which replaced several other directives going back to 1959) sets precisely defined parameters, allowing for little discretionary margin. This directive was complemented by others relating to more specific subjects.

There is a striking contrast between these provisions and those of the existing binding international sources. Thus, returning to one of the examples given above, whereas Article 6 of C115 merely establishes an obligation to set radiation exposure limits, the Radiological Protection Directive actually quantifies those limits. Overly simplistic as this example may be, its aim is to show that the EU law in this field has managed to achieve a far greater level of detail than that of the comparable international law sources, something which can be deemed undisputed.

There are probably many reasons for this greater depth of binding regulation, but the following two are, in all likelihood, at the top of that list. Firstly, it is a lot easier for a smaller number of states with relatively similar traditions and circumstances to agree on more precise rules. However, the importance of this factor should not be overestimated - let us not forget that we find within the EU widely diverging opinions and approaches to nuclear technology.

Secondly, whereas classical international law can only be adopted by the unanimity of the contracting parties, EU legislation may be adopted by a qualified majority of the member states. ${ }^{3}$ Together, these two factors drastically reduce the need for the kind of compromises that one finds at the level of classical international organisations.

Two other advantages should be kept in mind. On the one hand, the speed at which new rules are adopted and revised in the EU is much higher than at the global level - an essential factor for the regulation of a quickly evolving industry. On the other hand, EU law automatically falls within the sphere of the European Court of Justice (ECJ) - it is, by nature, subject to a mandatory dispute resolution mechanism, one that includes coercive powers that are entirely absent in international law (e.g., the power to apply fines to states that fail to correctly transpose a community directive). 
In what concerns nuclear safety, however, there has so far been no legislative intervention of the EU.

The EU Council of Ministers adopted two (nonbinding) resolutions in this field. The first, that of 22 July $1975,{ }^{4}$ started from the basis that "nuclear safety problems extend beyond the frontiers not only of Member States but of the Community as a whole." It then requested national authorities and operators to cooperate at the Community level to address the technological problems of nuclear safety and agreed on a plan to progressively harmonise safety requirements, ultimately through the adoption of binding provisions. The final step of that plan never came to pass.

The second resolution, that of 18 June 1992, ${ }^{5}$ revealed a newfound concern for the safety of nuclear installations in Central and Eastern Europe and took an evidently less interventionist tone that made no mention of the ultimate objective of binding regulation and simply urged the continuation of the process of consultation and cooperation.

It would appear that sometime between those two resolutions, it became disputed whether the Communities had the power to adopt binding rules in the domain of nuclear safety or whether it should do so. However, as will be shown below, there are hardly any grounds for the first part of that dispute.

Curiously, the Euratom Treaty does not explicitly foresee the adoption of binding rules in that domain. Indeed, there is no title or provision in that treaty specifically relating to the safety of nuclear installations.

The preamble of the Euratom Treaty sets as one of its objectives the creation of "the conditions of safety necessary to eliminate hazards to the life and health of the public" (arising from ionising radiation).

Article 2(b) foresees that the Community should "establish uniform safety standards to protect the health of workers and of the general public and ensure that they are applied." This general task is then elaborated in Chapter 3 of Title 2, which relates to health and safety.

Within that chapter, Article 30 foresees the adoption of basic standards "for the protection of the health of workers and the general public against the dangers arising from ionizing radiations". 'Basic standards' are said to mean: "maximum permissible doses compatible with adequate safety", "maximum permissible levels of exposure and contamination" and "fundamental principles governing the health surveillance of workers". Article 31 sets out the procedure for the adoption of those basic standards. Article 32 provides for the revision and supplement of the basic standards. Article 33 further foresees the consultation of the Commission prior to the adoption of national legislation in this domain to allow it to formulate recommendations with the goal of harmonisation.

To the untrained eye, it may seem that such provisions indeed do not allow for the adoption of Community rules on nuclear safety. However, the competences of the European Communities have for many years been interpreted with a functional approach. Stating it simply, it is settled case-law of the ECJ that such competences must be interpreted widely in the light of the objectives underlying them.

A distinction must be made between a power specifically awarded by the treaty and an objective defined by the treaty with no accompanying powers. In the first case, one applies the procedural provisions of the respective power-awarding provision (in the case at hand, the consultation procedure foreseen in Article 31 of the Euratom Treaty, 
requiring a qualified majority vote in the Council). In the second case, one must apply the general procedure foreseen in Article 203 of the Euratom Treaty (equivalent to Article 308 of the EC Treaty), which requires unanimity in the Council.

Aside from these general principles of EU case law, it should be kept in mind that the European institutions (including the member states represented in the Council) have for several decades accepted a very wide interpretation of the powers conferred by Articles 2(b) and 30 to 32 of the Euratom Treaty.

To begin with, the Radiological Protection Directive went far beyond what was listed as 'basic safety standards' in Articles 2(b) and 30, especially in what concerns the level of detail of its obligations. But aside from that directive, a potentially surprising number of other EU laws were adopted using the very same legal basis. These additional laws concerned:

- the early exchange of information in the event of a radiological emergency (Decision 87/600/Euratom)

- the maximum permitted levels of radioactive contamination of foodstuffs and of feedingstuffs following a nuclear emergency (Regulations 87/3954/Euratom, 89/944/Euratom and 90/770/Euratom)

- informing the general public in the event of a radiological emergency (Directive 89/618/Euratom)

- the protection of external workers (Directive 90/641/Euratom)

- the shipments of radioactive substances between member states (Regulation 93/1493/Euratom)

- the protection of persons subject to or involved in medical exposures (Directive 97/43/Euratom, which replaced Directive 84/466/Euratom)

- the safety of high-activity sealed and orphan sources (Directive 2003/122/Euratom)

- the supervision and control of shipments of radioactive waste and spent fuel (Directive 2006/117/Euratom, which replaced Directive 92/3/Euratom).

Quite significantly, with one notable exception, none of these laws were ever challenged before the ECJ by any of the institutions or member states as to the validity of their legal basis.

The (partial) exception was Regulation 87/3954/Euratom. The European parliament asked the court to annul that regulation on the basis that it should have been adopted (exclusively or simultaneously) under the current Article 95 of the EC Treaty concerning the establishment and functioning of the internal market. ${ }^{6}$ The practical consequence would have been that the Council would have had (back then) to 'cooperate' with the parliament, rather than merely 'consult' it. Thus, this dispute was about a balance of powers, rather than about the competence of the Community to adopt rules in that domain. In any case, the court concluded that the purpose of that regulation was "to protect the population against the dangers arising from foodstuffs and feedingstuffs which have undergone radioactive contamination" $" 7$ and that it was, therefore, accurately adopted exclusively under Article 31 of the Euratom Treaty. 
As to the European parliament's argument that Articles 30 et seq. of the Euratom Treaty "do not relate to so-called 'secondary' radiation, [...] but, on the other hand, concern only the protection of persons directly involved in the nuclear industry", the ECJ replied that there was:
"no support in the relevant legislation for that restrictive interpretation, which cannot therefore be accepted. The indications are rather that the purpose of the articles referred to is to ensure the consistent and effective protection of the health of the general public against the dangers arising from ionizing radiations, whatever their source and whatever the categories of persons exposed to such radiations." 8

In other words, the court endorsed the use of Article 31 of the Euratom Treaty as the correct basis for the adoption of any binding provisions aimed primarily to protect workers and the public from the dangers of ionising radiation. It did not seem at all bothered by the fact that the procedure foreseen in that article came in the context of a somewhat limited concept of 'basic standards'.

Previously, in a judgement from 1988, the ECJ had already stated that the provisions of Chapter 3 of Title 2 of the Euratom Treaty "form a coherent whole conferring upon the Commission powers of some considerable scope in order to protect the population and the environment against the risks of nuclear contamination".

In other words and to conclude this line of argument, it is impossible to argue that the EU is barred from regulating nuclear safety without simultaneously challenging the wide interpretation that has so far been followed by the European institutions and has been confirmed by the ECJ.

Indeed, the Luxembourg court seized an additional opportunity to decisively put an end to any ongoing dispute with its (by now) famous judgement in Case C-29/99. ${ }^{10}$

This judgement, in the relevant part, was aimed at clarifying the extent of Community competences for the purposes of the Community's ratification of the CNS. ${ }^{11}$ The ECJ concluded that those competences covered, inter alia, the issues addressed in the CNS provisions for the assessment and verification of the safety, siting, design, construction and operation of nuclear installations. That conclusion was based on the fact that it is impossible to achieve the protection objective "without controlling the sources of harmful radiation". ${ }^{12}$

In a famous dictum, the Court stated that:

"it is not appropriate, in order to define the Community's competences, to draw an artificial distinction between the protection of the health of the general public and the safety of sources of ionising radiation." ${ }^{\text {"13 }}$

It further clarified that:

"Even though the Euratom Treaty does not grant the Community competence to authorise the construction or operation of nuclear installations, under Articles 30 to 32 of the Euratom Treaty the Community possesses legislative competence to establish, for the purpose of health protection, an authorisation system which must be applied by the Member States. Such a legislative act constitutes a measure supplementing the basic standards referred to in that article." 14 
The final part of that quote seems most relevant, to the extent that it seems to resort more to Article 32 (measures to supplement the basic standards) than Article 31. This falls in line with the 'coherent whole' approach used in the Saarland judgement, even though not so much with the approach in Case C-70/88.

Through Article 32, the Community is empowered to supplement the basic standards, which necessarily implies going beyond the limited concept of basic standards presented in Article 30. This provision should be read together with Article 2(b) ("uniform safety standards to protect the health of workers and of the general public and ensure that they are applied").

This latter article imposes upon the Community an obligation to act, not just an objective. If we were to ignore the 'supplementary' provision of Article 32, there would be a flaw in the drafting of the Euratom Treaty, insofar as it would oblige the Community to adopt uniform standards in a domain while not providing a procedure for the adoption of those standards.

This interpretation of Article 32, seemingly proposed by the court, is also the best way to understand the European institutions' use of those provisions. In this regard, Advocate General Jacobs noted:

\footnotetext{
"Interpretation in the light of subsequent practice is a common feature of the interpretation both of international treaties and of national constitutions. An interpretation in the light of subsequent practice is particularly legitimate and appropriate where the provisions in question were drafted long ago, where they have not been amended since and where there is a common and consistent practice of all actors entitled to interpret, apply or modify the rules in question." 15
}

All arguments put aside, the fact remains that the ECJ has the final word in the interpretation of EU law and it believes that the Community does have the competence to regulate the safety of nuclear sources (including nuclear installations) and that this competence encompasses the creation of a harmonised authorisation system. Furthermore, it has based this competence on Articles 30 to 32 (not on Article 203).

The consequences of this judgement were discussed in a document prepared by the Council's legal service in October 2003. ${ }^{16}$ Most unfortunately, all of the substantial and interesting paragraphs of this document were deleted for unexplained reasons from the version that was made public.

One further question should be addressed at this point, namely, whether the principle of subsidiarity is met in what concerns the regulation of nuclear safety. As this is a shared competence, this principle is an essential requisite for the adoption of Community legislation. If it is not met, then the Community cannot act. We shall leave this issue, however, for the following section, where we will discuss the more general question of whether the EU should act.

\section{The need to move forward}

We have already mentioned the advantages of Community law over a classical international law approach to the regulation of nuclear safety. These may be summarised as the possibility for a greater depth of binding regulation that is potentially more quickly adopted and revised and subject to a mandatory dispute settlement mechanism. 
Such advantages, however, are dependent on achieving, in practice, the required qualified majority in relation to a proposed regulation that actually brings about something new and useful. As will be seen in the following sections, these requisites have so far not been met.

Abstracting from whether a solution would be politically possible, let us now address whether the EU should indeed try to ensure, in a binding manner, the highest level of safety in the nuclear installations of the member states.

The safety of a nuclear installation seldom concerns only the member state in which that installation is found. A significant accident will almost always carry risks of crossborder effects. For this reason, for example, it is already included in the Community acquis that whenever a nuclear installation is to be built in any of the member states, there must be an Environmental Impact Assessment that necessarily includes the consultation of potentially affected member states. ${ }^{17}$

This simple reality clearly illustrates that the principle of subsidiarity is met in this case. With merely national regulations, the right of all European citizens to the highest level of protection from exposure to ionising radiations cannot be guaranteed. A supranational solution is required. The supranational element is particularly important in the framework of a community of states where several have opted not to resort to nuclear energy and are, therefore, particularly unwilling to tolerate the risks arising from the nuclear installations in other states.

This latter point was particularly well illustrated in the dispute between Austria and the Czech Republic concerning the building of the Temelin power station. This dispute, mediated by the European Commission, was finally settled with a most unusual agreement that gave Austria a watching brief over the safety of the Czech nuclear power plant.

Thus, it is the small and non-nuclear states that would have the most to gain from an effective and far-reaching Community intervention in this domain. All in all, in fact, everyone should come out as winners. Everyone, that is, except for the operators wishing to prevent rises in safety costs and the national regulators unwilling to submit to a further level of supranational scrutiny.

At a time when the security of energy supply has become a pressing policy issue, a Community regulatory framework (going beyond the current requirements of international law) would go a long way to promote transparency and trust, two essential elements for the development of the nuclear industry. While each state would retain the power to opt for or against nuclear energy, as they do now, they would be that much more assured of the safety of the operation of nuclear facilities in other member states.

Furthermore, the absence of Community legislation in the area of nuclear safety has become, in the very least, a manifestation of incoherence. With detailed safety standards when it comes to radiological protection, sealed sources or transport of radioactive waste, to name only a few examples, and with a vast body of inspectors to guarantee Euratom safeguards, the EU's non-existent role in nuclear safety is a legislative black hole explainable only by the overpowering gravitational forces of the undisclosed national interests of some member states.

From a competitive perspective and in the context of a progressively more integrated European energy market, the creation of a level playing field for nuclear operators is essential to prevent distortions of competition arising from differing national regulations. 
Examples of the possible sources of competitive distortions are the level of costs corresponding to the safety requirements of each state or the options for the funding of decommissioning of nuclear power plants.

Finally, as the Commission has repeatedly pointed out ever since 2002, the creation of a Community framework for nuclear safety became all the more important following the inclusion of nuclear safety requirements in the accession criteria for new member states. Indeed, in order to be allowed into the EU, the new member states had to prove their compliance with nuclear safety standards that were not part of the Community acquis. Instead, a methodology for the assessment of that safety was developed specifically for this purpose by the Commission and it was formally accepted by the candidate countries, thus becoming binding upon them. The application of these criteria led, inter alia, to the forced closure of several nuclear reactors (in Bulgaria, Lithuania and Slovakia).

Given the rejection of the Commission's proposed nuclear package (see next section), nuclear safety has become just another example of the use of double standards in the Community's relations with current member states and with candidate countries. While both the assessment method itself and its justification were universally valid (i.e., equally applicable to new and old member states), its application only to some countries and reflected a balance of power, rather than sound policy. In the words of the Commission:

\begin{abstract}
"If there is no common reference framework for the monitoring of the recommendations in the post-accession period, the EU could be accused of differential treatment between the new and present Member States. For the former, the Union would have a watching brief over the safety of their nuclear installations while for the latter it would not intervene. Such a situation would not be fair." 18
\end{abstract}

Specifically in what concerns the management of radioactive waste, it should be noted that none of the member states has so far succeeded in finding a final solution for the storage of the most dangerous of that waste. The ever-increasing quantities of high-level radioactive waste temporarily stored in surface installations has become a serious concern, both because of the unacceptable burden it represents for future generations and for security reasons (particularly in the post-9/11 world order). The research on and implementation of final solutions for high-level radioactive waste are, by their very nature, areas where cooperation between states is highly desirable and efficient.

The real question, it seems, is not whether a Community regulatory intervention is possible or desirable, but rather what exactly should be the reach and content of that intervention not only in ideal terms, but also in terms of what would be acceptable to enough member states to achieve a qualified majority.

\title{
4 The Commission's nuclear package
}

Even before the judgement in Case C-29/99, ${ }^{19}$ the Commission had already started calling for the adoption of EU legislation on nuclear safety. On 6 November 2002, it adopted the Communication on Nuclear Safety in the European Union. ${ }^{20}$ The opening paragraph placed this legislative effort squarely within the context of European energy security issues. To this day, the attempt to adopt EU legislation on nuclear safety remains inextricably linked to the promotion of nuclear energy in the member states. This 
association is superfluous (if not even erroneous) and has made it far harder to achieve success in negotiations by triggering the animosity of non-nuclear states and some environmentalist Nongovernmental Organisations (NGOs) - precisely those with the strongest interest in the adoption of such a regulation.

The Commission's proposal was revised several times to take into account the suggestions of the different participants in the consultative procedure and, in essence, to try to reach a compromise solution that might finally be adopted by the Council. The final version of the proposal was adopted in September 2004. ${ }^{21}$

The history of the negotiations may be briefly summarised as that of a modest proposal progressively torn down until it was almost entirely deprived of merit and usefulness and was, even then, still unacceptable to a blocking minority.

The proposal was structured into two separate instruments:

1 the Proposal for a Council Directive laying down basic obligations and general principles on the safety of nuclear installations (hereinafter 'Safety Proposal')

2 the Proposal for a Council Directive on the management of spent nuclear fuel and radioactive waste (hereinafter 'Waste Proposal').

Since the objective of this paper is to look to the future, the content of these abandoned proposals shall not be discussed in detail. Rather, a synthesis of their content shall be presented, highlighting the most important features of their evolution from the original to the final draft together with the advantages and disadvantages they showed in relation to the existing international law documents (maxime CNS and Joint Convention).

\subsection{Safety proposal}

The proposed safety standards had four main sources of inspiration: the CNS (complemented by the nonbinding safety standards of the IAEA), the methodology developed by the Commission to assess nuclear safety in candidate countries, the work of the Nuclear Regulators Working Group and that of the Western Nuclear Regulators Association. These sources were to be complemented and fully articulated with the national experience relating to safety standards, maxime through the contributions of the Article 31 Group of Experts.

The initial proposal was to establish a framework directive to be completed later by subsequent directives ("a legal framework comprising a mechanism allowing an evolution"). Thus, the proposed first directive put forward minimum standards and general principles with the idea that, in time, this regulation would become more precise.

However, the reference to the future adoption of further directives (as well as the concept of framework directive) was dropped in the revisions. This was a clear sign that some member states were unwilling to go past that minimum level of regulation which the Commission had envisaged as merely a first (and clearly insufficient) step.

The scope of this directive would have been significantly wider than that of the CNS (which only encompasses nuclear power plants and other related facilities on the same sites), referring to civil facilities where nuclear material is present on a significant scale. The final draft, however, would allow each member state to freely exclude any installation from the Community requirements by also excluding it from national requirements. Without a Community concept of nuclear installation, the mandatory nucleus of this scope would, in effect, be reduced to the obligation arising from the CNS. 
The vast majority of the obligations foreseen in this proposed directive (the creation of a regulatory body, the establishment of a regulatory framework, the foreseen obligations for the license holders, including those in case of incidents or emergencies, the principle of priority of safety, the principle of prime responsibility for safety resting with the licensee and the availability of financial resources and adequate human resources) were virtually or at least functionally identical to the respective content of the CNS.

In some cases, the CNS is actually more specific in its requirements (e.g., the obligation to adopt measures to ensure safety in nuclear installations). Ironically, this is especially true in what concerns verification mechanisms, which was also one of the areas most badly hit by the revisions.

The initial draft required the annual submission to the Commission of national nuclear safety reports. More significantly, the Commission, resorting to a pool of national experts, would carry out verifications of the functioning of national safety authorities (not directly of the installations themselves). Even so, the verifications would have to be previously approved by the national authority in question. If any shortcomings were detected and notified to the member state, the latter would have three months to indicate the measures taken to address those issues (with a bridge being implicitly made here with the general infringement proceedings under the treaty). The Commission would also organise meetings with the member states to examine the reports and would periodically present an EU-wide report, gathering information from reports and verifications.

The reporting obligations were similar to those of the CNS, except that reports would have to be presented every year, rather than every three years. The verifications, limited as they may have been, were entirely innovative.

By the final draft, however, any sign of innovation or empowerment of the Commission had been systematically erased. The final text essentially reproduced the verification mechanism of the CNS in far less precise terms. Member states would simply present reports every three years, at the same time and basically (if not entirely) with the same content as the reports presented in the framework of the CNS. A committee of representatives of the national regulatory authorities would be established, with the Commission being reduced to a role of secretariat. The committee itself would have no actual powers; it would merely 'encourage' or 'recommend' what it saw fit to agree upon (expectably, by unanimity).

In short, the same reports would be discussed at the same time in two different forums with the same possible consequences. Ensuring the confidentiality of parts of the reports was also a concern of some member states.

As for innovative content, there is very little one can point to. There was an explicit obligation for the national regulatory authority to conduct safety inspections, including during decommissioning. This was absent from the letter of the CNS, although it can easily be seen in spirit (it is, indeed, indispensable to meet the general obligations on parties to ensure compliance with safety standards). The only other provisions worth mentioning are those concerning decommissioning, which will be analysed together with the ones from the following directive. 


\subsection{Waste proposal}

The scope of this proposal was identical to that of the Joint Convention, encompassing decommissioning activities. Once again, even though subject to the same obligations (whenever applicable), spent fuel was treated as a category separate from waste to take into account the differing policies of the member states in this respect.

The general obligations were very similar to those of the Joint Convention (taking all the necessary measures to ensure safety, keeping production of waste to a 'minimum practicable' level, ensuring public information and participation, etc.). Shipments of radioactive waste or spent fuel between member states or to third states would be allowed under the same conditions foreseen in the Joint Convention, with the positive difference that the state of destination would have to ensure compliance with the Community level of safety standards (in lieu of a mere requirement of a capable administrative, technical and regulatory capacity).

Member states would also be obliged to establish a 'clearly defined' waste management programme, which should include deadlines for the licensing of the development and operation of disposal facilities. This is innovative in relation to the Joint Convention (even though it can be argued that the same obligation derives from others included in the Convention), but its impact would be questionable, at the very least.

More importantly, the waste management programme requirements in the final version pale in comparison to the original draft. The Commission's initial proposal included an Annex with specifics on the steps for waste disposal. It imposed Community deadlines for licensing the development of disposal facilities (four years after the transposition deadline) and their operation (nine years after the transposition deadline for low and intermediate-level waste and 14 years for high-level waste). In other words, it set a deadline for member states to have permanent disposal facilities up and running (something which no member states has so far been able to accomplish), even though it explicitly allowed for those deadlines to be revised by the Council. It also imposed deep disposal in geological repositories as the Community solution for the permanent disposal of high-level waste (while leaving the door open for other solutions resulting from future technological developments). ${ }^{22}$ Failure to comply with these obligations would have serious financial consequences - Community funding under Chapter 4 of Title 2 of the Euratom Treaty would be withheld from states that had not made "significant progress towards the implementation of a programme of long-term management of all spent nuclear fuel and radioactive waste" ${ }^{23}$ All this was swiftly deleted.

As for the attitude towards decommissioning, ${ }^{24}$ it was slightly bold in the original draft and shy beyond belief in the final one.

The first draft imposed the 'polluter pays' principle - member states would have to ensure the availability of funds at the time of decommissioning (including cases wherein the originally responsible party would be incapable of paying) and these would have to come from the operators themselves ${ }^{25}$ and would have to comply with fairly precise criteria set out in an Annex. These criteria allowed for unilateral exceptions (effectively, member states deciding not to comply with these criteria), as long as they were notified within a certain deadline. This scheme only applied to commercial installations, each state being free to decide on the availability of resources for the decommissioning of other facilities. 
By the final draft, most of the relevant text had been deleted, including the Annex. All that remained was the obligation to ensure the availability of funds for decommissioning. Even the 'polluter pays' principle had fallen, with the explicit indication that funds could be available 'from the regulatory body and the operators'.

Finally, what was said about the reporting mechanisms in the safety proposal equally applies to the waste proposal, mutatis mutandis.

\subsection{General considerations}

Amazingly, the Community decision-making process, with its smaller number of parties and lower voting requirements, actually managed to produce documents that are often not as far-reaching nor as precise as the ones developed in a classical international forum (especially in the case of the waste proposal) and which, at the end of the day, contained no remarkable improvement in relation to the latter.

The language of the original draft was already typical of an international law document, with abundant use of undetermined concepts that chipped away at the binding content of the proposed directive. The revisions only reinforced this tendency. Those revisions clearly evidenced some common characteristics.

First, national authority was seriously strengthened, particularly the powers of national regulatory authorities, to the detriment of the Commission, which was quite simply deprived of any significant role and downgraded from watchdog to servile clerk.

Second, the proposed directives were brought much closer to the international conventions not just in language and content, but also in what concerns verification mechanisms.

Third, provisions were added or revised to reproduce the obligations already arising from the Community acquis, especially in what concerns radiological protection, emergencies and information and consultation procedures.

But nothing expressed the attitude of some of the member states better than the highly unusual step taken by three of them (Finland, Sweden and the UK) and later joined by two others (Germany and Belgium) to propose nonbinding resolutions to replace the Commission's proposal of directives. These member states constituted a sufficient blocking minority.

To conclude, what was intended as a modest beginning was, by force of negotiation, converted into a raggedy regulatory dead end. What could have been acceptable as a first step became highly questionable as the only foreseeable step in the near future. This meant that the Commission's proposal now gathered enemies on both sides of the barricades: those who wanted the EU regulation of nuclear safety said the proposal was essentially hollow and those who wanted the EU to stay clear of the sector thought that even a hollow tree could be a nuisance.

The Commission's nuclear package was finally shelved at the Council of Ministers meeting of 25 June 2004. The respective conclusions stated, in essence, that the member states were still committed to pursuing nuclear safety, but that this was primarily a national issue already coordinated through international conventions and organisations. The Council concluded that "instruments in this field should be developed following extensive consultations with stakeholders", taking into account "the work conducted by national nuclear regulatory authorities". ${ }^{26}$ No deadline or even tentative timeframe was 
set for the supposed wide-ranging discussions and consultations that should follow. It was a text that represented almost exclusively the perspective of the 'internationalist' current within the Council (those who want the Community to stay clear from control of nuclear safety).

Precisely for that reason, some member states felt the need to add their own declaration to these conclusions. Austria, Italy and Luxembourg wanted the Council to have defined the way forward (with a firm schedule and clear assignment of responsibilities) and called on the Commission to renew its initiative to set legally binding common safety standards which should be of "added value in comparison with existing international instruments". ${ }^{27}$

\section{The high-level group}

\subsection{The Council's position}

It did not take long before the issue was back on the Council's agenda, probably more because of the Russian energy fright than of any substantial change in the position of the member states. The discussion was officially kick-started by a decision at the highest level. The European Council made it clear from the beginning that Community intervention would not imply imposing nuclear energy on any member state that wished to remain non-nuclear. ${ }^{28}$ But the awe-inspiring failure of the Commission's nuclear package just three years earlier deprived the Commission of the political authority required to put forward a new proposal or, in the very least, cautioned the use of a different method for the preparation of a proposal which could please enough member states.

In May 2007, the Council of Ministers adopted the conclusions with instructions for further action on this subject. ${ }^{29}$ The most curious aspect of these conclusions was their implication for the balance of powers between the European institutions.

Legally, it is the Commission that holds the monopoly of legislative initiative. It is also the Commission alone that may create the committees required for the accomplishment of its tasks (Article 135 of the Euratom Treaty).

There is, therefore, an eerie scent of real politik to the Council conclusions of May 2007 , to the extent that they implicitly ordered the Commission to exclude itself from the decision on the proposal of a new nuclear safety directive and set limits for the use of powers that are exclusive to the Commission, quoting no legal basis. Those conclusions also effectively set up a legislative proposal method different from the one imposed in Articles 30 to 32 of the Euratom Treaty.

Still, it is important to keep in mind that these Council conclusions were not legally binding on the Commission. Thus, any discrepancy between the Council's conclusions and the Commission's actual decision is irrelevant, with only the latter having legal force in this respect. Revealingly, many - including some of the members of the High-Level Group (HLG) itself - believe that the HLG was created by the Council of Ministers and that it somehow reports to it rather than to the Commission.

As 'decided' by the Council, the issue of future Community action on nuclear safety was to be discussed by an HLG made up of the heads of the national nuclear regulators and by one representative of the Commission, who would also provide secretarial 
services. Nothing was foreseen as to the voting procedure, which would have to be decided by the HLG itself, even though the silence of the law clearly favoured the choice for unanimity.

The HLG would be a stable body, not just a temporary forum to be disbanded after coming to an agreement on a proposal. Indeed, it determined that the HLG would have to present a report (to the Council and European parliament) two years after its creation, with other reports following at least every three years thereafter.

The Council set substantial limits to the discussions to be developed within the HLG not only through the setting of mandatory requirements ("decisions concerning safety actions and the supervision of nuclear installations" would have to "remain solely with the operators and national authorities" and the proposal would have to bring an "added value compared to the activities undertaken in international contexts"), but also through the adoption of a list of possible actions, from which the HLG would have to choose which to proceed with.

These actions were drafted clearly from an 'internationalist' perspective. There is no actual mention of the drafting of common standards, much less of a binding directive, even though it was clear to everyone that the HLG would be picking up where the Commission's nuclear package had left off. This is an important feature, since it suggests that the Council was not intending to restart negotiations on the nuclear package so much as it was trying to find nonbinding alternatives in the realm of cooperation.

According to the Council's conclusions, the HLG would limit itself to discussing how to promote the existing international frameworks and efforts (NSC, Joint Convention, IAEA, OECD/Nuclear Energy Agency (NEA), Western European Nuclear Regulators Association (WENRA), etc.) within the EU, at the most compiling a list of Community best practices (something also found at the international level). EU-level discussions were perceived as complementary to the discussions in international forums and they would be followed by no more than recommendations and requests for feedback, much like at the international level.

The two only concrete proposals that seemed to result from this list of actions were:

1 the promotion of transparency and access to information on nuclear safety, inclusively through the creation of an EU website

2 the coordination of the work programmes of member states and the Commission in the field of nuclear safety by means, if appropriate, of respective information management tools concerning international nuclear safety programmes.

\subsection{The Commission's position}

With Decision 2007/530/Euratom of 17 July 2007, the Commission established the 'European High Level Group on Nuclear Safety and Waste Management'. As was to be expected, it did not divert significantly from what had been outlined by the Council.

The only differences worth mentioning are the following:

- $\quad$ reports should be submitted every two years to the Commission, which will forward them to the Council and the European parliament (rather than directly to the latter institutions) 
- only a two-thirds qualified majority is required for the adoption of the Rules of Procedure with the concurrence of the Commission, which made it feasible for the HLG to stipulate that it would decide by a qualified or even simple majority, rather than by unanimity

- the mission of the HLG was defined as assisting "the Commission in progressively developing common understanding", but also in creating "eventually additional European rules in the field of" nuclear safety.

There is no doubt in anyone's mind that the Commission remains firmly in favour of the adoption of EU legislation on nuclear safety and waste management. After meeting the appointed chairman of the HLG, Commissioner Andris Piebalgs said it was "essential [for] the members of the HLG [to] agree on common principles governing nuclear safety, which will ensure a solid basis for the Group's future activities". ${ }^{30}$

What is not so clear, at this point, is whether the Commission retains any excitement for or, indeed, even interest in the legislation that stands a chance of being accepted by enough member states. It is also to be seen whether the Commission has bowed its head to the Council and agreed to forget about the initiatives for nuclear safety legislation, handing over custody of that field to the national regulators, gathered in a EU forum governed by classical international rules.

\subsection{Current discussions within the $H L G$}

The HLG had its first meeting in October 2007. Apparently, there was never a formal decision on the voting rule (due to disagreement between member states) which, in effect, means that decisions are taken by unanimity.

This is, in itself, sufficient to draw conclusions on what might come to be recommended by the HLG. If even with qualified majority voting, the negotiations for the Commission's nuclear package became so firmly marked by the 'internationalist' trend, there is hardly any hope for a significant Community approach to be issued by the unanimous vote of a body of representatives of the national regulatory authorities. It seems the only way a document will actually be adopted is if the majority bows to the demands of the blocking minority, which would mean giving up hope of any meaningful EU regulation of nuclear safety.

In the most recent meeting, at the end of May $2008,{ }^{31}$ the member states supposedly "committed themselves for further improvements" to nuclear safety. The optimistic language of the press release forgets to highlight that the members of the HLG are not empowered to commit their member states to concrete measures (at most, they can commit their respective regulatory authorities) and that the so-called commitments contain no traces of significant Community action beyond what is already foreseen at the international level and what was required by the Council and the Commission. Thus, they committed themselves to:

- information exchange and the drawing of common lessons following international review processes under the CNS and the Joint Convention

- developing a self-assessment and subsequently inviting an IAEA Integrated Regulatory Review Service (IRSS) (peer review) to review the legislation and arrangements in their regulatory body (a process that can take years before it reaches 
all the member states) - incidentally, the reason why this was acceptable to all member states, whereas the Commission's proposal for Community inspections of the regulatory authorities was not, is that an IRSS is carried out only at the request of the state in question and it has virtually no significant legal consequences

- $\quad$ work together, cooperate and develop further measures (especially the establishment and implementation of radioactive waste management plans in all member states)

- create an EU webpage to simplify access to nuclear safety information - something which had already been required by the Council.

To put it simply, the HLG has so far reached no significant decision. The dynamics of the HLG have tended to favour the 'internationalist' side of the dispute, to the point that, so far, none of the member states that usually represented the Community perspective has been able or willing to push for its own position.

France submitted a rough draft of a Community instrument that can be summarised as follows:

- member states should comply with the fundamental principles of the CNS and with those set out in an Annex ${ }^{32}$ - the content of that Annex is a faithful reproduction of the content of the final version of the Commission's safety directive proposal minus the initial definition of scope and the monitoring and reporting provisions

- member states would actively and fully participate in CNS review meetings, making their reports publicly available

- WENRA's work would take into account the fundamental principles and would be used as basis for discussions within the HLG, whose secretariat would be provided by national safety authorities (rather than by the Commission)

- the HLG would: facilitate the exchange of good practices, monitor and promote WENRA activities, harmonise the form and content of the reports of EU states under the CNS, discuss the results after each CNS conference and make recommendations, study IAEA reports to derive common lessons, create a website for information on nuclear safety and advise the Commission on any such issue

- the HLG would present a triennial report to the EU institutions, to be tabled before parliament and discussed at the Council (strengthening of the link to the Council and severance of ties to the Commission)

- National Regulatory Authorities (NRAs) would initiate a staff exchange policy financed by the EU

- $\quad$ member states would invite an IAEA IRSS by March 2009.

France's proposal achieves the appearance of forward movement while actually ensuring a long-term freezing of the status quo. It brings no improvement to the substance of nuclear safety rules applicable throughout the EU, just as the Commission's final proposal would not have. As for procedural arrangements, it excludes the Community from the field altogether, eliminating even the overly watered-down monitoring and reporting provisions of the Commission's proposal. Discussions would take place at the IAEA and WENRA levels, with the HLG merely accompanying those debates and playing an accessory role. In its attempt to keep the Commission far away 
from this issue, the proposal actually goes as far as to foresee that secretariat services would be provided by national authorities and for reporting to be done to the Council. Obviously, the objective is to enshrine nuclear safety as a domain with no significant Community intervention and where negotiations should follow classical international rules (maxime unanimity).

As for contributions to the improvement of nuclear safety in the EU, this proposal contained only two points of interest: one, the obligation to invite an IAEA IRSS (even though what would be truly interesting would be a similar procedure carried out by the Commission, followed by binding requirements rather than mere recommendations - again, 'cooperation to achieve safety' is chosen over 'obligation to achieve safety') and two, the creation of a staff exchange programme between national regulators.

Incidentally, while the members of the HLG did subsequently commit themselves to invite an IRSS, as was mentioned above, that commitment was not made in a legally binding manner and it also contained no deadline.

The repeated proposal for the creation of an EU website is particularly revealing of the objective of the 'internationalist' approach: to create the appearance of Community intervention (hopefully leading to greater public trust) while guaranteeing the long-term absence of any actual interference.

\section{Which type of instrument?}

In discussing what type of legislative intervention should be taken by the EU in the field of nuclear safety, the following basic options may be taken into consideration:

Option A no intervention

Option B nonbinding instrument

Option C directive based on and similar to the CNS and Joint Convention

Option D general framework directive based on the CNS and Joint Convention (detailed safety standards to be developed later)

Option E detailed directive.

Two further elements should be included in this consideration of options.

The first is the scope of the instrument: limited to commercial nuclear power plants, as in the CNS (represented as '-') or wider, as in the Commission's nuclear package (represented as ' + ').

The second is the existence of monitoring and reporting provisions which, when they do exist, are either limited to reproducing international mechanisms (represented as ${ }^{\text {(1) }}{ }^{(1)}$ ) or include actual supervision by the Commission (represented as ${ }^{\text {(2) }}$ ).

Under this system of classification, the following evolution of the specific proposals put forward so far may be observed:

2003: Initial Commission proposal

$D+{ }^{(2)}$

2003: UK/Finland/Sweden proposal

$B$

2004: Final Commission proposal

$C+{ }^{(1)}$ 
2004: Result of Council negotiations on Commission proposal

The HLG's Working Group on Improving Nuclear Safety Arrangements has carried out a most needed discussion around those options. An attempt was made to systematically reflect on the pros and cons of those possible types of regulatory intervention.

But the discussion seemed to be biased beforehand by the choice of assessment criteria. Thus, five criteria were used to assess each possible instrument, which can be summarised as follows:

1 Does it contribute to a high level of nuclear safety?

2 How does it affect national regulators and regulatory requirements?

3 Does it affect the efficiency of national regulators?

4 What is its impact on cooperation and information exchange? What is its impact on transparency?

5 What is its impact on the existing international mechanisms?

The main problem with these criteria is that two of them are essentially identical and relate to an issue which has been distorted. The question is not whether a certain instrument would affect national regulators more, but rather, which type of instrument would best serve the ultimate objective of achieving a high level of nuclear safety. It may just be that the best solution would be to have a Community regulator, especially for licensing procedures, whose decisions would then be implemented on the national level by simpler structures than the ones that are presently in place. Those criteria set off from the false premise that national regulators must be strong and unrestrained, whereas that is only one possible model.

Specifically (and contrary to what has been argued by some), the CNS is fully compatible with the emergence of a supranational regulator or of some other form of division of tasks between the national level and the Community level. This idea must be duly stressed: while it is true that under existing international law, nuclear safety is primarily a national responsibility, nothing prevents the sharing of those responsibilities with a supranational structure in order to achieve better efficiency. If it were otherwise, the Community would never have been allowed to join the CNS.

Also, it is very difficult to make abstract impact assessments based on the types of instruments, since their consequences often depend on the content rather than the type. The analysis too often must be made in terms of the 'potential' impact, which may lead to the wrong conclusions (e.g., just because one instrument has a potential negative impact under one criterion does not mean that the others have a real advantage over it if that potential impact can be eliminated in the content of the instrument).

Finally and most importantly, there seems to have been an overcomplication of a rather simple issue.

From the Community perspective, intervention in the domain of nuclear safety should be aimed at ensuring the conditions of safety necessary to eliminate hazards to the life and health of the public, namely through the establishment of uniform safety standards (Preamble and Article 2(b) of the Euratom Treaty), as well as, to a lesser degree, ensuring a level playing field for competitors in the EU energy market. From the 
national perspective, the concerns should be to ensure a high level of safety of national facilities, as well as of facilities based in other member states, while retaining freedom of choice in issues of essential strategic interest (e.g., choice between nuclear and non-nuclear power). Of course, an additional concern, from both perspectives is to have an instrument that is compatible with existing international efforts, but that is not particularly difficult - indeed, all the concrete proposals that have been made so far would have ensured that outcome.

Having defined the objectives as such, it must be acknowledged that Option A and Option $B$ would in no way improve the existing international framework of cooperation and would not significantly contribute to any of the Community or national objectives.

As for Options $C$ to $E$, it seems difficult to dispute that a directive with precise obligations (as long as they were in line with the IAEA and WENRA requirements and did not impose unreasonable restrictions on the regulatory options of each member state) would do more to guarantee safety, as well as confidence in your neighbours' safety, than a directive with only general obligations.

The member states that oppose the adoption of precise rules have never been able to provide a convincing explanation for their opposition. Their attempts at explanations become almost ironic when one considers the preciseness of the Community legislation in the field of radiological protection or the extent of the Community's oversight and inspection in the field of nuclear security (safeguards).

This being said, the fact remains that, so far, no proposal falling under Option $E$ has ever been put forward, not even by the Commission. One reason for this may be that member states were clearly not willing to go that far. Another reason may be that such a proposal, aside from being very difficult to put together, would have offered countless reasons for small disputes at the negotiations table.

Strategically, given the current context, it makes sense to leave the definition of detailed obligations for a later stage (i.e., Option D), when the Commission's role in nuclear safety has been more solidified. Naturally, this strategy only works if the Commission is given a role in nuclear safety, something which several proposals have been openly trying to avoid. It would work best if it is given a broad scope and accompanied by actual powers of supervision (i.e., Option $D+{ }^{(2)}$ ).

Option $C$ is significantly less interesting than $D$ and $E$. With no requirement of specification of the rules in the near future, one could expect that state of affairs to last a long time. But even Option $C$ could offer significant added value over the existing international mechanisms if the following requisites were met:

- its scope should be wider than that of the CNS (+)

- it should include verification mechanisms (at least over the national regulators, if not over the facilities themselves) managed by the Commission $\left({ }^{(2)}\right)$.

It should also be kept in mind that any directive, even if limited to stipulating the general principles already included in international treaties (i.e., basic Option C), would have the merit of rendering those principles truly binding and enforceable. Although it would take several years, the interpretative powers of the ECJ would probably lead to a deepening of the regime and the existence of the infringement procedure (with the possibility of fines being applied to member states who failed to comply with any obligation under the directive) would ensure compliance, something which the existing international framework is completely incapable of doing. 


\section{Conclusion}

Something is awry in the EU decision-making process relating to nuclear safety.

Would not most EU citizens not feel safer knowing that the nuclear power plants in the Community were not just subject to national rules and control, but also to Community rules and oversight? It seems to be fairly common sense to have a supranational watchdog guarding the national watchdogs, especially in a continent that felt firsthand the consequences of allowing national regulators free reign in the management of the safety of their nuclear power plants. 'Cooperation to achieve safety' is by no means as useful as an effectively enforceable and verifiable obligation to achieve safety.

The absence of Community legislation on nuclear safety is not explained by a struggle between states with and without nuclear power plants. The blocking minority is made up of Western member states with nuclear power plants and well-established national regulators (Belgium, Finland, France, Germany, the Netherlands, Sweden, UK). But other states with such characteristics are found in the opposite field, maxime Italy, Spain and most of the new member states. Why have these states assessed their national interest so differently from the others? Are there characteristics that justify this discrepancy?

Throughout this paper, we have seen that member states have accepted binding and very precise Community legislation in several neighbouring areas, maxime radiological protection. It is now beyond dispute that the regulation of nuclear safety is a competence shared between the member states and the Euratom Community and that there are several justifications for the desirability of a Community intervention.

More to the point, it seems to be only the 'old' member states that are fighting the adoption of binding rules and overview mechanisms, whereas they felt no problem in including such rules and mechanisms in the accession procedure of new member states. This makes their unwillingness to submit to the same type of scrutiny particularly hypocritical.

As for deciding what shape that intervention should take, we have shown that only a binding instrument (i.e., a directive) would bring any significant added value. Since it seems entirely unreasonable, in the present context, to adopt a directive with detailed rules on nuclear safety, the best option would seem to be a framework directive based on the CNS (but with a wider scope) and on WENRA documents, with a specific procedure and timeline for the development of further rules and accompanied by a verification mechanism managed by the Commission $\left(\right.$ Option $\left.D+{ }^{(2)}\right)$. This is more or less what the Commission was proposing with the initial version of its nuclear package.

But it is not likely that enough votes could be counted for such a proposal. What is most important is for the silent majority to refuse anything under a basic Option C (directive merely reproducing international principles, with a reduced scope and no verification mechanisms). That option would still be meritorious, especially if the ECJ were given opportunities to specify the content of its obligations.

New member states must make their partners accountable on the same terms as themselves, eliminating the discrimination in nuclear safety requirements based on when they joined the EU. Non-nuclear states must claim their right to guarantee that another state's choice for nuclear energy does not endanger their citizens by adopting a binding supranational framework comparable to the ones that already exist in so many other areas 
which much smaller risks. Nuclear states that have so far been in favour of Community regulation must not give in to the temptation of settling for whatever instrument is possible right now.

The political reality seems to be that there are seven member states known for usually pursuing the 'internationalist' approach. This is more than enough to constitute a blocking minority to any Community intervention which would bring a reasonable improvement to the current situation. On top of this, the other 20 member states have been oddly passive in their approach to these negotiations.

One must wonder if the best possible outcome for the discussions of the HLG would be no outcome at all. At this point, a refusal to adopt any instrument which would fail to bring significant improvements (anything less than Option $C$ ) is probably the best outcome that the majority can hope for. It would deprive the blocking minority of the desired effect of the appearance of Community intervention and would also prevent the freezing of legislative developments for years to come.

The strangest feature of this entire process seems to be, in what concerns some member states, the detachment between the calculation of national interest and the likely opinion of their citizens. This is made possible only because of a lack of transparency and publicity of the entire procedure, fuelled by the fact that no one seems to be interested in and capable of bringing this discussion to the public.

Negotiations were made harder by the choice of interlocutors. The same discussion would probably have a very different outcome if it took place between the representatives of the environment ministries of the member states. Since states decided to be represented by the very people whose powers and authority would be restricted by the legislation under negotiation, it is hardly surprising for the result to be a sturdy defense of the status quo.

We must now wait and see what proposals come out of the HLG and what will be the Commission's reaction to those proposals. From the Commission's perspective and from the perspective of anyone who would like to see nuclear safety promoted at the EU level, surely it must be better to have no intervention (at the moment) than to have an illusion of intervention which would only serve to postpone any real solution for several years. The worst possible outcome for the current negotiations would be to put consultations and discussions of nuclear safety at the EU level exclusively in the hands of national regulators, to the detriment of the Commission.

\section{Notes}

1 It should also be kept in mind that the IAEA's safety standards do become binding upon states in the framework of specific joint projects or cooperation with that agency.

2 Also relevant, even if not so directly, is the Occupational Cancer Convention (C139) of 24 June 1974, currently with 37 contracting parties.

3 Article 31 of the Euratom Treaty.

4 OJ C 185/1, 14 August 1975.

5 OJ C 172/2, 08 July 1992.

6 Judgements of the ECJ of 22 May 1990 and 4 October 1991, European Parliament v. Council (C-70/88), ECR (1990) I-2041 and ECR (1991) I-4529.

7 Judgement of 4 October 1991 in Case C-70/88, paragraph 12.

8 Idem, paragraphs 13 and 14. 
9 Judgement of the ECJ of 22 September 1988, Saarland et al. (C-187/87), ECR (1998) 5013, paragraph 11 .

10 Judgement of the ECJ of 10 December 2002, Commission v. Council (C-29/99), ECR (2002) I-11221 (hereinafter 'Judgement C-29/99').

11 Whenever the European Communities ratify an international treaty, they are obliged to submit a declaration clarifying the distribution of competences within the relevant field between the Communities and the member states.

12 Judgement C-29/99, paragraph 76.

13 Judgement C-29/99, paragraph 82.

14 Judgement C-29/99, paragraph 89.

15 Opinion of Advocate General Jacobs in Case C-29/99, paragraph 148.

16 See Council Doc. No. 13909/03.

17 Council Directive 85/337/EEC of 27 June 1985 on the assessment of the effects of certain public and private projects on the environment, as revised by Council Directive 97/11/EC of 3 March 1997.

18 Communication from the Commission to the Council and the European Parliament on Nuclear Safety in the European Union, 6 November 2002, COM(2002) 605 final (hereinafter '2002 Communication'), p.10.

19 But already taking into account the conclusions of Advocate General Jacobs in that case.

202002 Communication.

21 Amended proposal for a Council Directive (Euratom) laying down basic obligations and general principles on the safety of nuclear installations and amended proposal for a Council Directive (Euratom) on the safe management of the spent nuclear fuel and radioactive waste, 8 September 2004, $\operatorname{COM(2004)~} 526$ final (hereinafter '2004 Communication'). For 2003 versions, see: $\operatorname{COM}(2003) 0032$ final.

22 The option for deep disposal was replaced by the following text in the final version, a perfect example of the tragicomedic style often found in the revisions: the member states should "study the possibility to give priority to the solution of deep geological disposal" (our underlining).

232004 Communication, p.36.

24 Also taking into account the provisions of the safety proposal.

25 Another significant motivation for this rule was concern on the distortion of competition resulting from state intervention, in the context of a fully integrated EU energy market.

26 See Doc. no. 10823/04, paragraph 5.

27 Idem, Annex B.

28 See the Presidency Conclusions for the Brussels European Council of 8/9 March 2007, available at http://www.consilium.europa.eu/uedocs/cms_Data/docs/pressdata/en/ec/93135 .pdf, p.23 (Doc. No. 7224/07).

29 See Doc. no. 8784/07.

30 See press release IP/08/270 of 20 February 2008.

31 See press release IP/08/907 of 9 June 2008.

32 Even though the provisions of an Annex have the same legal force as the provisions of the main body of text, the transfer of certain content to an Annex has long been used as a method of psychologically downgrading the relevance of those provisions. A known example of this phenomenon was observed with the downgrading of the European Charter of Human Rights from a Title (in the draft constitution) to an Annex (in the Lisbon Treaty). 